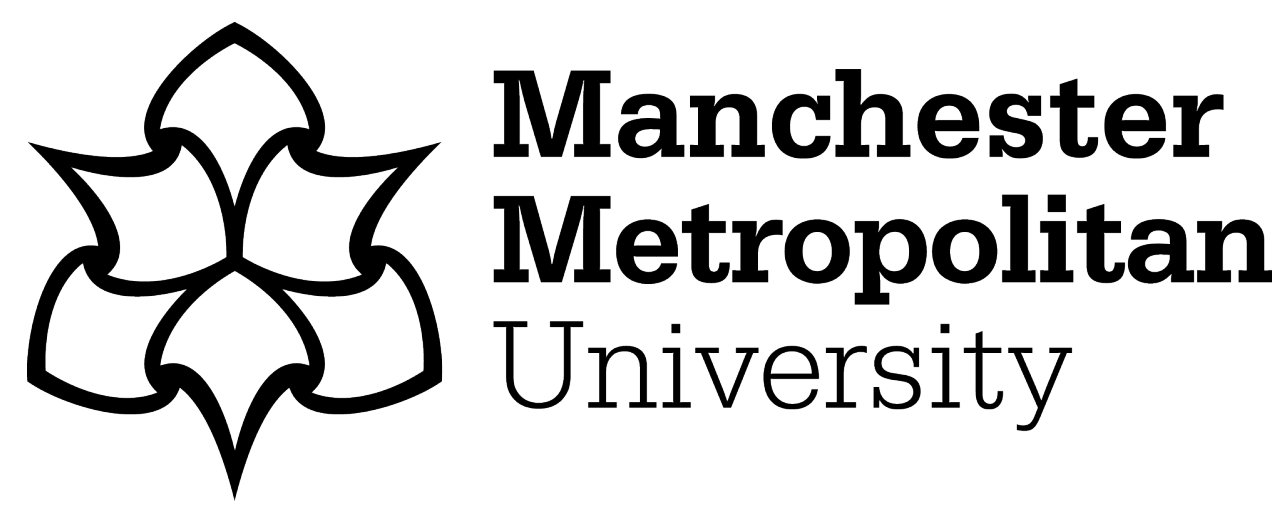

Brown, SJ, Boulton, Andrew JM, Bowling, Frank L and Reeves, Neil D ORCID logoORCID: https://orcid.org/0000-0001-9213-4580 (2018) Exercise Training to Target Gait Unsteadiness in People with Diabetes. In: 79th Scientific Sessions of the American Diabetes Association, 22 June 2018 - 26 June 2018, Orlando, USA.

Downloaded from: https://e-space.mmu.ac.uk/625482/

Publisher: American Diabetes Association

DOI: https://doi.org/10.2337/db18-576-P

Please cite the published version 
Authors: Brown S, Boulton AJM, Bowling FL, Reeves ND

Character limit (not including spaces): 1,800

Current character count: 1,790

\section{Exercise training to target gait unsteadiness in people with diabetes'}

Balance impairment and an associated high fall rate in people with diabetes is common, and a huge burden to quality of life and healthcare systems. Causes of impaired balance are commonly attributed to both sensory and motor deficits, which includes impaired muscle strength and function. This study investigated the effects of resistance exercise training on balance control during walking over level ground and on stairs. Ten DM people (age: 62yrs, BMI: $29 \mathrm{~kg} / \mathrm{m}^{2}$, VPT: $9 \mathrm{~V}$ ) and 6 DM people with DPN (age: $59 \mathrm{yrs}, \mathrm{BMI}: 27 \mathrm{~kg} / \mathrm{m}^{2}$, VPT: $31 \mathrm{~V}$ ) performed a 16-week intervention of weekly resistance exercise training to increase ankle and knee extensor muscle strength. Six DM controls did not take part in the intervention (age: $50 \mathrm{yrs}, \mathrm{BMI}: 26 \mathrm{~kg} / \mathrm{m}^{2}$, VPT: $12 \mathrm{~V}$ ). Balance during gait was quantified before and after the intervention, by separation between the body centre-of-mass and centre-of-pressure under the feet during both level and stair walking. Knee and ankle extensor muscle strength was assessed using a dynamometer. The exercise intervention increased strength of ankle plantar flexors $(22 \%)$ and knee extensors (30\%). Despite the increases in lower limb muscle strength produced by the intervention, no improvements in balance were seen post training. However, gait speed did increase by $8 \%$, which previous research has shown to be associated with quality of life. Controls showed no training effects in any variables. Although this exercise intervention had a positive effect on gait by increasing walking speed, there was no effect on the control of balance. Previous research has identified that medio-lateral (side-to-side) balance is impaired in people with DPN. The muscles exercised in the present study mainly control the major sagittal plane (forwards-backwards) movements that occur during gait. Interventions targeting the lateral stabilising muscles of the hip and trunk, may show greater potential efficacy in redressing the balance impairment of this population. 